Article

\title{
Are Opera Singers Fit or Not?
}

\author{
Jacopo Junio Valerio Branca ${ }^{+}\left(\mathbb{D}\right.$, Massimo Gulisano ${ }^{*}{ }^{\dagger}$, Mario Marella ${ }^{\dagger}$ and \\ Gabriele Mascherini 1
}

Department of Experimental and Clinical Medicine, Anatomy and Histology Section, University of Florence, 50134 Florence, Italy; jacopojuniovalerio.branca@unifi.it (J.J.V.B.); mario.marella@unifi.it (M.M.); gabriele.mascherini@unifi.it (G.M.)

* Correspondence: massimo.gulisano@unifi.it; Tel.: +39-055-275-8069

+ These Authors contributed equally to the work.

Received: 7 April 2020; Accepted: 16 May 2020; Published: 21 May 2020

check for updates

\begin{abstract}
Little information is available about the physical fitness of opera singers. The aim of this study is to measure cardiac engagement during rehearsals and to test both cardiovascular fitness and body composition in a group of opera singers. Thirty-two opera singers ( 17 female and 15 male) were enrolled for the assessment of body composition by bio impedance, of cardiovascular fitness by submaximal exercise test on a cycle ergometer and the physical effort during singing. Anthropometric parameters showed an overweight condition mainly due to an increase in fat mass. Watts reached during the cycle ergometer test were below the normal range for the general population. During rehearsals, singers have reached $95 \%$ of the maximum heart rate. Nowadays, opera singers show low levels of physical fitness, but singing is an activity that requires a high heart effort. Therefore, it is recommended to involve such professionals in a gradual and individualized physical training program in order to avoid fatigue during performances and achieve a better singing performance.
\end{abstract}

Keywords: aerobic training; singing; physical fitness; heart rate; physical effort of singing

\section{Introduction}

In 2008, the New York Times published an article entitled "Singing and Fitness" [1]. This article hypothesized an indirect role of the effects of singing, especially lyrical, on the cardiovascular, pulmonary and hormonal systems. In particular, lyrical singers seem to have some kind of protection against body weight accumulation because the physical stresses caused by their activity promote a strengthening of the chest cavity muscles, a greater pulmonary capacity, better cardiac functionality and an increase in leptin hormone secretion. This article states that even if it has not yet been demonstrated, singing in an opera requires great physical effort due to the continuous moving onstage, sometimes even with heavy costumes. Consequently, being in a good physical condition helps to achieve a better performance by avoiding physical and mental fatigue [1].

The other side of the same coin is knowing the performance, having information about the physical effort required, in order to plan a correct training program. However, to date, the cardiovascular effort to which opera singers are subjected during rehearsals is not yet known and cardiac activity during singing has been monitored only in two studies [2,3]. In particular, in these studies heart activity was associated only with breathing, of which the main outcome was heart rate variability and the aim of these studies was to verify how singing promotes a better state of wellbeing.

In addition, nowadays, the literature has only partially investigated the parameters of physical fitness related to health in this particular population. Therefore, the question posed by the article in the New York Times, "is singing exercise?", is still unanswered. To test the level of opera singers' training, many studies have used respiratory functionality tests. The results are not conclusive, but 
they show a slight prevalence of higher expiratory functionality in singers when compared to reference values for the general population [4]. When respiratory functionality tests are considered in the context of cardiorespiratory fitness, a study performed on marathon runners compared the same expiratory functionality parameters with the general population without reporting any significant differences; therefore, these assessments appear to provide only inconclusive information [5].

A recent preliminary study of Ksinopoulou et al. [6] reports for the first time the parameters of cardiovascular fitness in opera singers. An incremental cycle ergometer test was performed: the results for maximum oxygen consumption showed parameters lower than the normal range for the general population matched for age and sex. However, to the authors' knowledge, this is the only study that has studied the cardiovascular fitness of this population.

Another important parameter of physical fitness related to health is body composition. Currently, studies on body composition values in opera singers have not yet been carried out; usually studies on this population report only a description of the sample with anthropometric parameters such as height and weight, without any description of the different body compartment.

Since there are currently no published papers on the physical fitness of opera singers, the aim of this study is to report, for the first time, the cardiorespiratory and body composition parameters of an international level group of singers.

\section{Materials and Methods}

\subsection{Participants}

Thirty-two opera singers (17 female and 15 male) were enrolled during three consecutive international musical masterclasses from 2015 to 2017 held by Corso d' Opera in Montepulciano (Italy). The singers were from Italy, Ukraine, Korea, the United States and Russia and were professional singers.

All participants provided written consent. The approval of the Human Research and Ethics Committee of the University of Florence was obtained. The study is in accordance with the Declaration of Helsinki.

\subsection{Procedures}

\subsubsection{Body Composition Analysis}

The study of body composition attempts to separate and quantify body weight or mass into its basic components. Methodology used for the assessment of body composition was performed by the integration of anthropometry and bioelectrical impedance of the whole body analysis [7].

Anthropometry parameters were weight, height and Body Mass Index (BMI, $\mathrm{kg} / \mathrm{m}^{2}$ ). In addition, waist circumference was taken with a non-extendable metric tape, flexible and accurate (Holtain Limited, $1.5 \mathrm{~m}$ Flexible Tape) [8].

Whole-body bioelectrical impedance analysis (BIA) is an analysis of the resistance generated in soft tissues as an opposition to the flow of an injected alternate current and it is measured by skin electrodes at the hand and foot level (BIA 101 Sport Edition, Akern, Florence, Italy). Resistance (RZ, $\Omega$ ) is the opposition to the flow of an injected alternating current, at any current frequency, through intraand extracellular ionic solutions, while reactance $(X C, \Omega)$ is the dielectric or capacitive component of cell membranes and organelles, and tissue interfaces: therefore, changes in impedance measurements reflect changes in hydration and cell mass. Phase Angle (PA; in degrees) is the ratio between RZ and $\mathrm{XC}$ and represents the relationship between intra- and extracellular volumes. In addition, starting from RZ and XC parameters we estimate the following body compartments parameters: fat free mass (FFM in $\mathrm{kg} / \mathrm{m}$ ), body cellular mass (BCM in $\mathrm{kg} / \mathrm{m}$ ), fat mass ( $\mathrm{FM}$ in $\mathrm{kg} / \mathrm{m}$ ), total body water (TBW in $\mathrm{L} / \mathrm{m}$ ) and extracellular water (ECW, \% TBW) [9]. 


\subsubsection{Cardiorespiratory Fitness}

The evaluation of cardiovascular fitness was carried out with a submaximal test by a cycle ergometer, while the evaluation of respiratory functionality was made by spirometry.

Each subject performed an incremental submaximal test on the cycle ergometer. Before starting the test, the heart rate corresponding to $75 \%$ of the predicted maximum was checked for each subject [10]. After wearing a heart rate monitor (Zephyr Technology, Annapolis, MD, USA), the subject started pedalling with a resistance of 20 watts at the baseline, maintaining a pedalling frequency of 50-60 rpm. Then, after every minute, the pedalling load was increased of 20 watts: the test terminated when the heart rate achieved the previously calculated value ( $75 \%$ of the predicted maximum). This test was repeated three times with two minutes of recovery time between each set in order to also evaluate the ability to recover from physical effort. Moreover, this parameter is useful for understanding the level of fitness. The duration (seconds) and the distance traveled (meters) was recorded for each test [11].

The tests of respiratory functionality were performed by a portable spirometer (Med Graphics, CPX Express) to achieve a forced expiratory volume in one second (FEV1), a forced vital capacity (FVC), mean forced expiratory flow (FEF) during the middle half of the FVC (FEF 25-75\%) and the percentage of FEV1/FVC. The best of at least two tests, reproducible to within $5 \%$, was accepted. The spirometry was repeated at least three times or until duplicate values were obtained which agreed within 5 percent, and the best reproducible values of FEV1 (percentage predicted) and FVC (percentage predicted) were used in the analysis [12]. The FEF 25-75\% accepted was obtained from the single test with the greatest sum of FEV and FVC. Values gained from the tests of pulmonary functionality were reported as a percentage of the predicted value. The predicted values of Miller (1986) were used [13].

\subsubsection{Physical Effort during Singing}

During a dress rehearsal, the physical effort of opera singers was assessed. Before starting the rehearsals, each singer put on a heart rate monitor (Zephyr Technology, Annapolis, MD, USA) at the chest level that was taken off at the first break. The data on a monitored performance lasting 10 minutes were downloaded. The maximum heart rate (HR max), the maximum respiratory rate ( $R R$ max) and the maximum body temperature (BT max) were analyzed.

\subsubsection{Theory/Calculation}

Data are expressed as mean and standard deviation. The body composition values were compared for age and sex of the general population [14]. To test the level of fatigue of opera singers between the three tests at the cycle ergometer an ANOVA test was performed. In addition, cardiovascular fitness data were compared between males and females with the two-tailed Student's $t$-test to evaluate if the performances of the two genders were different [13]. The respiratory functionality tests were compared with the reference values for age and sex. In order to verify the presence of a significant difference of opera singers compared to the predicted values, a paired sample Student's $t$-test was performed. The parameters of maximum heart rate, maximum respiratory rate and maximum body temperature detected during the singing dress rehearsal were compared with reference to the standard physiological parameters.

\section{Results}

The results on body composition are shown in Table 1. Body composition parameters also show a group with good cellular hydration and health but with an increased fat mass compartment (FM: Female $=20.8 \pm 4.4 ;$ Male $=11.8 \pm 3.2 \mathrm{~kg} / \mathrm{m}$ ). 
Table 1. Anthropometrics and body composition parameters of opera singers enrolled.

\begin{tabular}{ccccc}
\hline & Female & Normal Range & Male & Normal Range \\
\hline Age $(\mathrm{yrs})$ & $28.1 \pm 4.6$ & & $34.1 \pm 6.2$ & \\
\hline Height $(\mathrm{cm})$ & $166.5 \pm 6.3$ & & $177.3 \pm 6.7$ & \\
\hline Weight $(\mathrm{kg})$ & $69.4 \pm 16.1$ & & $86.3 \pm 6.1$ & \\
\hline BMI $\left(\mathrm{kg} / \mathrm{m}^{2}\right)$ & $25.1 \pm 6.4$ & $18.5-25$ & $28.8 \pm 3.2$ & $18.5-25$ \\
\hline Waist c. $(\mathrm{cm})$ & $84.5 \pm 11.4$ & $<88$ & $95.8 \pm 13.8$ & $<102$ \\
\hline RZ $(\Omega)$ & $555.2 \pm 96.7$ & & $432.9 \pm 27.2$ & \\
\hline XC $(\Omega)$ & $60.8 \pm 8.3$ & & $54.7 \pm 8.8$ & \\
\hline PA $\left({ }^{\circ}\right)$ & $6.3 \pm 0.7$ & $5.8-7.4$ & $7.3 \pm 1.1$ & $6.7-8.3$ \\
\hline FFM $(\mathrm{kg} / \mathrm{m})$ & $30.8 \pm 3.6$ & $23-28$ & $39.2 \pm 2.5$ & $28-35$ \\
\hline TBW $(\mathrm{L} / \mathrm{m})$ & $22.5 \pm 2.7$ & $15-22$ & $28.8 \pm 2.9$ & $18-26$ \\
\hline ECW $(\%)$ & $44.4 \pm 3.1$ & $39-45$ & $40.8 \pm 3.9$ & $38-44$ \\
\hline BCM $(\mathrm{kg} / \mathrm{m})$ & $17.1 \pm 2.9$ & $10-17$ & $23.2 \pm 1.9$ & $14-21$ \\
\hline FM $(\mathrm{kg} / \mathrm{m})$ & $20.8 \pm 4.4$ & $7-14$ & $11.8 \pm 3.2$ & $4-9$ \\
\hline
\end{tabular}

Legend: BMI = Body Mass Index; Waist c. = waist circumference; RZ = resistance of flow injected by bioimpedance analyzer; $\mathrm{XC}=$ reactance of flow injected by bioimpedance analyzer; $\mathrm{PA}=$ phase angle; $\mathrm{FFM}=$ fat-free mass; $\mathrm{TBW}=$ total body water; $\mathrm{ECW}=$ extracellular water; $\mathrm{BCM}=$ body cellular mass; $\mathrm{FM}=$ fat mass .

The parameters on cardiovascular fitness recorded on cycle ergometer test show better results in females than males. These parameters with higher results in females were maximum power achieved at the cycle ergometer at $75 \%$ of maximum heart rate (Female $=61.3 \pm 19.3$; Male $=48.9 \pm 17.1$ watts, $p<0.05$ ), the distance covered (Female $=1029.3 \pm 300.2 \mathrm{~m}$; Male $=838.2 \pm 405.7 \mathrm{~m} ; p<0.05$ ) and the duration (Female $=180.3 \pm 72.8$; Male $=145.4 \pm 72.1 \mathrm{sec} ; p<0.05$ ). The ANOVA test shows that both the second and third test record statistically lower values than the first test in both genders (Figure 1).

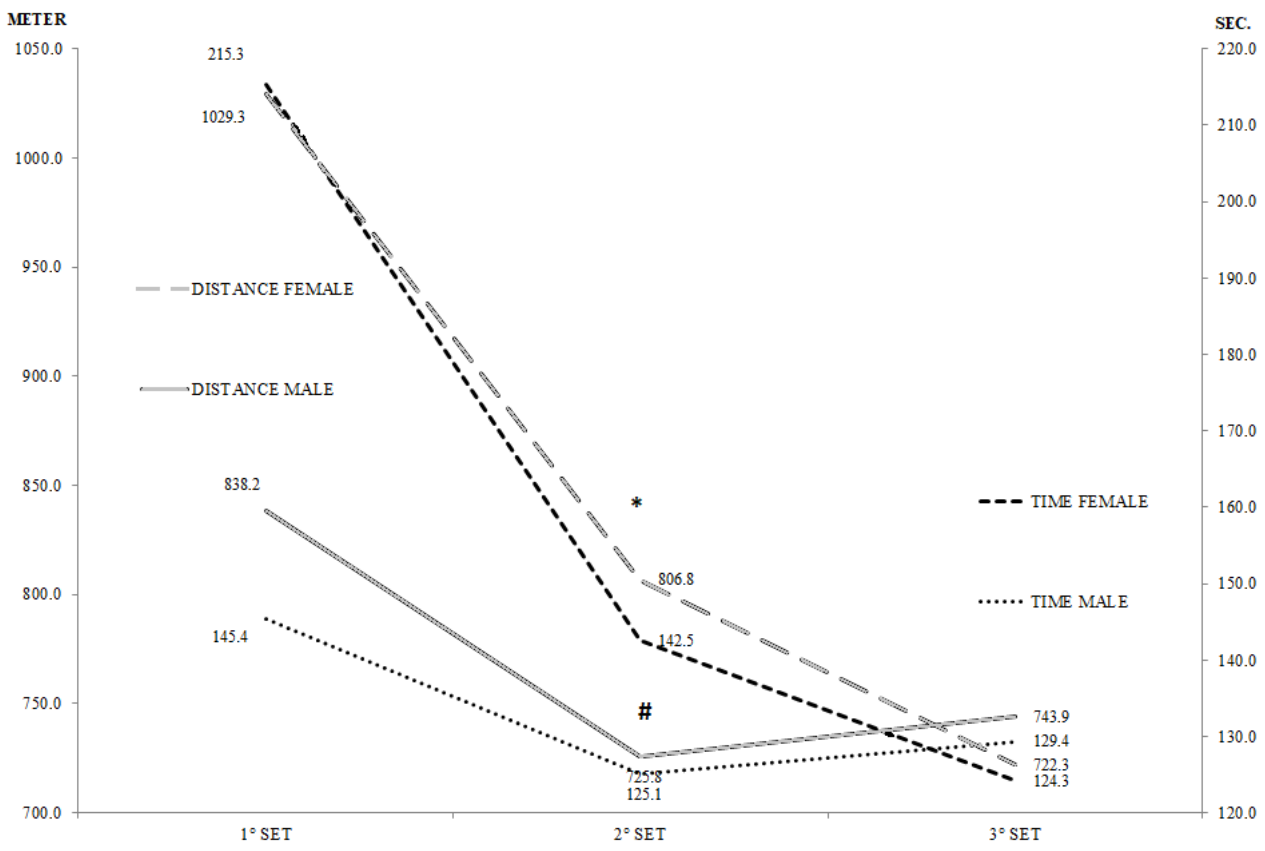

Figure 1. Results of cardiovascular fitness expressed as distance covered and time required during an incremental cycle ergometer test. * statistical difference (ANOVA test) of the distance covered during the three set of cycle ergometer test. \# statistical difference (ANOVA test) of the duration during the three set performed on the cycle ergometer test. 
Table 2 shows the respiratory functionality results. Both males and females showed normal parameters, without significant differences compared to the values predicted for age and sex.

Table 2. Comparison of respiratory function tests of sample with predicted values.

\begin{tabular}{ccccccc}
\hline & Female & Predict & $\boldsymbol{P}$ value & Male & Predict & \multicolumn{1}{c}{ value } \\
\hline FVC (L) & $3.9 \pm 0.9$ & 4.0 & NS & $4.7 \pm 0.7$ & 5.1 & NS \\
\hline FEV1 (L/sec) & $3.3 \pm 0.6$ & 3.4 & NS & $4.1 \pm 0.7$ & 4.4 & NS \\
\hline FEV1/FVC (\%) & $85.1 \pm 10.6$ & 84.7 & NS & $86.8 \pm 5.4$ & 82.4 & NS \\
\hline FEF25/75 (L/sec) & $3.8 \pm 1.3$ & 3.6 & NS & $4.4 \pm 1.3$ & 4.3 & NS \\
\hline
\end{tabular}

Legend: FVC = forced vital capacity; FEV1 = forced expiratory volume in one second; FEV1/FVC = ratio Tiffeneau-Pinelli index; FEF25/75 = mean forced expiratory flow during the middle half of the FVC; FEF Max = the maximum instantaneous flow achieved during a FVC maneuver.

The results of the singing dress rehearsal evaluation are shown in Table 3. All three parameters analyzed showed an increase compared to the physiological values at rest. However, the heart rate increased about $80 \%$ compared to the resting values, while the respiratory rate and body temperature showed a lower increase, about $24 \%$ and $2.5 \%$ respectively.

Table 3. Results of heart rate, respiration rate and body temperature recorded for 10 minutes of an opera singing test. These results were compared with the normal values at rest.

\begin{tabular}{ccccc}
\hline & Female & Values at rest & Male & Values at rest \\
\hline HR max $(\mathrm{bpm})$ & $180.0 \pm 8.3$ & $60-100$ & $178.0 \pm 13.3$ & $60-100$ \\
\hline RR $\max (\mathrm{bpm})$ & $19.8 \pm 3.5$ & $12-16$ & $19.2 \pm 4.0$ & $12-16$ \\
\hline $\mathrm{T} \max \left({ }^{\circ}\right)$ & $37.9 \pm 0.2$ & 37 & $37.9 \pm 0.1$ & 37 \\
\hline
\end{tabular}

Legend: $\mathrm{HR} \max =\operatorname{maximum}$ heart rate; $\mathrm{RR} \max =$ maximum respiratory rate; $\mathrm{BT} \max =$ maximum body temperature.

\section{Discussion}

Currently, little information is available about the physical effort required during opera singing and the consequent fitness parameters of opera singers. Our sample involved people who had been professional opera singers for more than five years and, therefore, the parameters of physical fitness related to health should be considered stable. The results of the present study on cardiovascular fitness confirmed the preliminary data gained by Ksinopoulou et al. [6] and those obtained on respiratory functionality are in accordance with the literature [15]. However, the present study reported for the first time the body composition parameters of opera singers, both female and male, and their physical effort during singing.

The sample showed anthropometric parameters at the upper limit of the normal range. The analysis of body composition by bioelectrical parameters (in particular the phase angle), despite a high fat mass, reported good cellular health, also confirmed by good cell mass and correct compartmental distribution of body water.

A central (or upper body) pattern of fat distribution is negatively associated with airway function, while increases in body muscular mass result in linear increases for all spirometric variables in healthy persons [16]. The waist circumference and fat-free mass are in the normal range, therefore the results of the spirometric tests can be associated with good functionality. In particular, these results are not different to those predicted for a sample of the general population matched for age and sex.

In order to verify cardiovascular fitness, we assessed the ability to perform a physical activity up to a moderate intensity, as well as the ability to recover from physical effort and then to repeat it. The amount of time needed to reach $75 \%$ of the maximum heart rate was 3 minutes for females and 2 minutes and 25 seconds for males. It is therefore clear that opera singers show a low level of 
cardiovascular fitness, since the maximum watts achieved during an incremental test on the cycle ergometer were lower than the predicted values [17]. Another indicator of a low level of fitness is the difficulty in recovering from an effort and then repeating it; both the second and third tests on the cycle ergometer showed significantly lower values than the first one.

As a result, it may be assumed that singing does not involve a significant heart effort; however, heart rate is the parameter that increases the most during the 10 minutes of monitoring carried out during the dress rehearsal, achieving $95 \%$ of the maximum predicted for age and sex. Respiration rate and body temperature increased moderately. The hypothalamus, which is our brain thermostat, regulates the body temperature at $37^{\circ} \mathrm{C}$ with the possibility of adjustments of $\pm 1{ }^{\circ} \mathrm{C}$ [18]. Considering that during the performance singers are on a stage with spotlights and heavy clothes, the increase of $1{ }^{\circ} \mathrm{C}$ should be considered reasonable. A respiratory rate between $12-16$ breaths per minute is considered a resting value [19]. Opera singing has particularly long expiratory phases; it is therefore reasonable to record the respiratory frequencies slightly above the resting values. Therefore, if the results for BT max and RR max can be considered as expected values, the HR max values recorded in rehearsals lead us to conclude that there is a high heart effort for opera singers. Females show better results in both body composition parameters and cardiovascular fitness tests. The sample investigated features a lower age for females than for males, however, the age range is within early adulthood. Therefore, the difference in the aforementioned parameters seems more correlated to lifestyle, such as diet and physical activity performed.

Considering the results for cardiovascular fitness and HR max recorded during the rehearsals, we can state that aerobic training seems both necessary for increasing the level of fitness in opera singers and is functional to the activity they usually perform.

Aerobic exercise, such as walking, jogging, cycling and aerobic gym courses, seems the best training for developing heart-lung strength and endurance. In order to achieve aerobic fitness it is necessary to perform enjoyable exercise and practice training continuously for 30 to 50 minutes, three to five times per week, at $60 \%$ to $80 \%$ of your maximum heart rate, as suggested by the guidelines of the American College of Sports Medicine [20].

In order to improve physical fitness, the guidelines also recommend including resistance training [21]. Muscular conditioning is an important component in maximizing health but a correct technique in all exercises should be carefully followed in order to avoid bothersome neck or shoulder tension [22]. A resistance training program should be focused on the number of repetitions and not on the amount of weight lifted. At the beginning of a resistance training program, weights should be lifted for one session of 10-15 repetitions. Each exercise session should train eight muscle groups two to three times a week [20].

During a long performance, physical fatigue may occur, defined as peripheral, which can firstly present as gasps after having sung using a microphone. The perseverance of peripheral fatigue can lead to central fatigue, with a consequent loss of decision-making ability and readiness, thus compromising the performance definitively [23]. To avoid this, it is necessary to achieve and maintain good physical fitness, which enables the singer to deal with the high cardiovascular effort required for opera performances.

The present study shows some strengths. Firstly, nowadays it is the only study evaluating cardiac engagement during a rehearsal of opera singers; moreover, assessments were made to establish the level of physical fitness, including body composition. Secondly, the number of subjects who have undergone the assessments is in line with current studies. Finally, the homogeneity of the sample is an advantage; indeed, all the subjects performed singing regularly at an international level.

On the other hand, a limitation of the study is the use of a submaximal test to evaluate cardiorespiratory fitness. However, this was chosen to ensure the safety of the singers, as the study was not carried out in a clinical setting because the evaluation was not for health reasons. In addition, the sample is composed of singers of different races, which could limit the generalization 
of the results; however, this allowed us to obtain this sample size with such homogeneity with respect to the international level of performance.

The results obtained entail new directions of study in this field. The first one could be to verify the effectiveness, in terms of singing performance, of an exercise program for this specific population. Subsequently, it is possible to check whether any improvements are more sensitive to training in muscle strength or aerobic endurance.

\section{Conclusions}

The combination of vigorous singing with intense physical recitation requires good physical fitness. In addition, roles that are more active require additional energy and motor skills. Since singers act in different types of productions, often physical charm is also required. Nowadays, the public and producers demand singers who are similar to the characters they perform, thus, it is difficult for an overweight actor to get the role of Butterfly. Having good physical fitness has become a key element for a successful career as an opera singer.

Author Contributions: Conceptualization and data curation, M.M.; Formal analysis, visualization and writing—original draft, G.M.; supervision and validation M.G.; writing—review \& editing, J.J.V.B. All authors have read and agreed to the published version of the manuscript.

Funding: This research received no external funding.

Conflicts of Interest: The authors declare no conflict of interest.

\section{References}

1. Claiborne Ray, C. Singing and fitness. New York Times, 1 April 2008. Available online: http://www.nytimes. com/2008/04/01/science/01qna.html(accessed on 4 March 2020).

2. Vickhoff, B.; Malmgren, H.; Aström, R.; Nyberg, G.; Ekström, S.R.; Engwall, M.; Snygg, J.; Nilsson, M.; Jörnsten, R. Music structure determines heart rate variability of singers. Front. Psychol. 2013, 4, 334. [CrossRef] [PubMed]

3. Grape, C.; Sandgren, M.; Hansson, L.O.; Ericson, M.; Theorell, T. Does singing promote well-being?: An empirical study of professional and amateur singers during a singing lesson. Integr. Physiol. Behav. Sci. 2003, 38, 65-74. [CrossRef] [PubMed]

4. Schorr-Lesnick, B.; Teirstein, A.S.; Brown, L.K.; Miller, A. Pulmonary function in singers and wind-instrument players. Chest 1985, 88, 201-205. [CrossRef] [PubMed]

5. Mahler, D.A.; Moritz, E.D.; Loke, J. Ventilatory responses at rest and during exercise in marathon runners. J. Appl. Physiol. 1982, 52, 388-392. [CrossRef] [PubMed]

6. Ksinopoulou, H.; Hatzoglou, C.; Daniil, Z.; Gourgoulianis, K.; Karetsi, H. Ergospirometry Findings in Wind Instrument Players and Opera Singers. Int. J. Occup. Environ. Med. 2017, 8, 60-61. [CrossRef] [PubMed]

7. Mascherini, G.; Petri, C.; Galanti, G. Integrated total body composition and localized fat-free mass assessment. Sport Sci. Health 2015, 11, 217-225. [CrossRef]

8. Marfell-Jones, M.J.; Stewart, A.D.; de Ridder, J.H. International Standards for Anthropometric Assessment; International Society for the Advancement of Kinanthropometry: Wellington, New Zealand, 2012.

9. Kyle, U.G.; Bosaeus, I.; De Lorenzo, A.D.; Deurenberg, P.; Elia, M.; Manuel Gómez, J.; Lilienthal Heitmann, B.; Kent-Smith, L.; Melchior, J.C.; Pirlich, M.; et al. ESPEN, Bioelectrical impedance analysis—Part II: Utilization in clinical practice. Clin. Nutr. 2004, 23, 1430-1453. [CrossRef] [PubMed]

10. Tanaka, H.; Monahan, K.D.; Seals, D.R. Age-predicted maximal heart rate revisited. J. Am. Coll. Cardiol. 2001, 37, 153-156. [CrossRef]

11. Fletcher, G.F.; Ades, P.A.; Kligfield, P.; Arena, R.; Balady, G.J; Bittner, V.A.; Coke, L.A.; Fleg, J.L.; Forman, D.E.; Gerber, T.C.; et al. Exercise standards for testing and training: A scientific statement from the American Heart Association. Circulation 2013, 128, 873-934. [CrossRef] [PubMed] 
12. Redlich, C.A.; Tarlo, S.M.; Hankinson, J.L.; Townsend, M.C.; Eschenbacher, W.L.; Von Essen, S.G.; Sigsgaard, T.; Weissman, D.N. American Thoracic Society Committee on Spirometry in the Occupational Setting. Official American Thoracic Society technical standards: Spirometry in the occupational setting. Am. J. Respir. Crit. Care Med. 2014, 189, 983-993. [CrossRef] [PubMed]

13. Miller, A. Pulmonary Function Test in Clinical and Occupational Disease; Grune \& Stratton: Philadelphia, PA, USA, 1986.

14. Barbosa-Silva, M.C.; Barros, A.J.; Wang, J.; Heymsfield, S.B.; Pierson, R.N., Jr. Bioelectrical impedance analysis: Population reference values for phase angle by age and sex. Am. J. Clin. Nutr. 2005, 82, 49-52. [CrossRef] [PubMed]

15. Thompson, B.R.; Johns, D.P.; Bailey, M.; Raven, J.; Walters, E.H.; Abramson, M.J. Prediction equations for single breath diffusing capacity (Tlco) in a middle aged caucasian population. Thorax 2008, 63, 889-893. [CrossRef] [PubMed]

16. Maiolo, C.; Mohamed, E.I.; Carbonelli, M.G. Body composition and respiratory function. Acta Diabetol. 2003, 40, S32-S38. [CrossRef] [PubMed]

17. Usaj, A.; Kandare, F. The oxygen uptake threshold during incremental exercise test. Pflugers Arch. 2000, 440, R200-R201. [CrossRef] [PubMed]

18. Obermeyer, Z.; Samra, J.K.; Mullainathan, S. Individual differences in normal body temperature: Longitudinal big data analysis of patient records. BMJ 2017, 359, j5468. [CrossRef] [PubMed]

19. Barrett, K.E.; Ganong, W.F. Ganong's Review of Medical Physiology, 25th ed.; McGraw-Hill Medical: New York, NY, USA, 2012; p. 619.

20. Franklin, B.A.; Whaley, M.H. ACSM's Guidelines for Exercise Testing and Prescription, 6th ed.; Lippincott Williams \& Wilkins: Philadelphia, PA, USA, 2000.

21. McArdle, W.; Katch, F.I.; Katch, V.L. Exercise Physiology: Nutrition, Energy, and Human Performance, 8th ed.; Wolters Kluwer Health: Riverwoods, IL, USA, 2014.

22. Eller, N.; Skylv, G.; Ostri, B.; Dahlin, E.; Suadicani, P.; Gyntelberg, F. Health and lifestyle characteristics of professional singers and instrumentalists. Occup. Med. 1992, 42, 89-92. [CrossRef] [PubMed]

23. Amann, M. Central and peripheral fatigue: Interaction during cycling exercise in humans. Med. Sci. Sports Exerc. 2011, 43, 2039-2045. [CrossRef] [PubMed]

(C) 2020 by the authors. Licensee MDPI, Basel, Switzerland. This article is an open access article distributed under the terms and conditions of the Creative Commons Attribution (CC BY) license (http://creativecommons.org/licenses/by/4.0/). 